\section{JSCN T \\ Journal of Sustainable Construction \\ Materials and Technologies}

\title{
A Research Study on Prevention of Occupational Accidents in the Construction Sector during the Design Process
}

\author{
Özge Yaşara , Yeliz Tülübaş Gökuç,** \\ ${ }^{a}$ Institute of Science and Technology, Balikesir,10145, Turkey \\ ${ }^{b}$ Department of Architecture, Balikesir University, Balikesir, 10145, Turkey
}

Manuscript Received November 6, 2019; Accepted January 29, 2020

\begin{abstract}
Safety by design has recently become one of the most significant research topics. It is believed that safety by design will provide profits to the construction sector by improving efficiency, reducing operating costs, reducing hazards and risks, and decreasing expensive accident prevention methods on the site. The aim of this study is to determine the awareness of the safety by design in the Turkish construction sector, and to raise awareness of the importance among the professional stakeholders in order to anticipate occupational accidents at the design stage, and implement the accident prevention applications early in the design process. Because the construction sector is hasty and fast, pre-construction executions have always been perceived as a waste of time, and the issue of prevention through design, which is the subject of this study, also takes place in the pre-construction stage. Due to the fact that the work related to the health and safety of the workers takes time and creates financial requirements, it is sometimes perceived as unnecessary by employers. Particularly, small-scale construction companies, make investments on safety only to protect themselves from legal sanctions. In order to identify the awareness of safety by design among the stakeholders in the sector, the data required for this study were collected through a questionnaire. The results of this study show that although the sector awareness on safety by design has emerged, there is still a huge gap in terms of implementation. It will be possible to fill this gap by increasing the awareness of the designers (architects, civil engineers) and increasing the legal supervision and penal sanctions.
\end{abstract}

Keywords: safety by design; safe design; safety through design; occupational accidents; construction sector ${ }^{\dagger}$

\section{Introduction}

From the beginning of the working life to the present day, workers have lost their lives due to work-related accidents or caught by occupational diseases. Statistically, construction remains the most dangerous industry in many countries [1;2]. When the occupational accidents statistics are analyzed, it is seen that the most accidents occurred in the construction sector. In addition to their damages to human life, occupational accidents cause significant financial damage to businesses and accordingly to the national economy and society. In particular, the low level of education of the majority of workers in the construction sector and the lack of necessary awareness and competence increase occupational accidents significantly. In the USA, the construction sector employs roughly $7.5 \%$ of the nation's workforce, but accounts for $20 \%$ of the nation's occupational related deaths[3]. According to the report of the Occupational Health and Safety Council in Turkey, construction and road works rank second in most of the deaths occurred in different business lines in 2018 with a rate of 23\%[4]. Construction workers are at three times higher the risk of fatality and two times higher the risk of injury[5]. The companies in

\footnotetext{
${ }^{*}$ Corresponding author:

E-mail address: yeliztulubas@hotmail.com (Y. Gökuç)

This study is derived from the master thesis prepared by the first author under the supervision of the second author.
} 
the construction industry are mostly small and medium-sized enterprises, and in terms of workers young male and informal workers are commonly seen in the sector. Especially in these days, construction is one of the leading sectors in which Syrian and Afghan migrant workers are employed.

Safety by design is a new concept in the construction sector, and it is an effort that is made in the design phase of a construction project to aim the prevention of occupational injuries and fatalities. Preventing occupational accidents through decisions made at the design stage is a process in which engineers and architects consider the safety of construction workers during the design process. The concept of the safety by design is the essence of safety. The aim of the safety by design is to reduce the risk of injuries, illnesses and damages to acceptable levels. By this way, improved efficiency will be ensured, operating costs and significant risks will be reduced and expensive protection practices will be avoided in construction industry[6,7]. Theoretically, prevention through design is the most effective approach to reduce occupational accidents at construction sites[8].

\section{Safety by Design}

It is seen that the concept of Safety by Design takes place in the literature as safety by design, safe design or prevention through design. In this study, safety by design is defined as eliminating or mitigating safety and health hazards in construction site by analyzing the design before the construction commences, and informing about all the unsolved hazards to project owner, construction worker and all end-users of the project. Research has shown that almost $60 \%$ of fatal accidents are caused by decisions made upstream from the construction site[9]. In the construction industry, which is considered to be the sector with the highest occupational accidents and risky working environments all over the world, it is difficult and costly to take precautions at the construction site during construction. Therefore, occupational safety needs to be considered to make the working environment safer before the construction begins.

Toole and Gambatese (2008) describe design for construction safety as a process in which engineers and designers explicitly consider the safety of construction workers during the design process[7]. In their study, it is emphasized that designing for occupational safety is another means of designing, and it is an outstanding tool not only for preventing accidents, but also for providing targets of design, safety, cost, timing and quality. The design team does not have enough information about identifying safe alternatives at the construction site, furthermore they have little knowledge of how to ensure safety by design. The main goal of safety by design is to reduce hazards that contributed to the fatal incident, injury, illness and environmental risks by integrating decisions that affect safety, health and the environment at all stages of the design process. The reduction of occupational accidents can be achieved by integrating hazard analysis and risk assessment methods with the concept of safety by design from the beginning of the design and engineering phases. Integration is an important step for the objective of reducing risk of injury and hazard to an acceptable level, eliminating them or providing information to the persons concerned.

Occupational safety is an issue that is not considered until the construction commences or any hazardous incident occurs, and from this point of view, the effect of designers (civil engineers, architects) on work safety is completely ignored. However, the design of the project clearly provides data about how the project will be actualized, and how the project subcomponents with work items will be brought together. In fact, designers unwittingly determine how construction work items will be applied. However, the vast majority of designers lack this awareness. Safety by design considerations for occupational safety is a new concept in many countries around the world, not just in Turkey. For instance, this concept is introduced into regulations in the UK, and it is on the initiative of individuals in the USA. Designers have a severe lack of knowledge about occupational safety. They usually find the chance to focus on occupational safety and health issues in design-build construction projects. Also, they can work with colleagues who are responsible for the construction of such projects[10].

Some studies in the literature show that consideration of occupational safety in the early design stages has a significant effect on occupational safety[11;12]. Studies have proven that design errors have been the root cause of construction accidents that have resulted in the death of workers[13]. In a study by Dalton(2002), fatal accidents in Ireland between 1991 and 2001 were examined, and it was found that 54 deaths occurred due to falls from height due to poor design of the building[14]. According to a study in the United States, design was linked to $42 \%$ of 224 fatal accidents from the period of 1990-2003[15]. The results of a study in the UK also show that 47 out of 100 accidents may be related to design rather than site safety considerations.

In Turkey, there are few studies on this subject. In his study, Gursoy (2014) examined the safety by design implementations in the world and in Turkey[16]. In this study, safe design components for the construction sector was analyzed, existing guidelines were reviewed, and finally a safety through design model compatible with 
Turkish legislation was developed within the framework of risk management. The results show that construction accidents can be reduced during preliminary project phases. In this sense, the study makes an important contribution to the literature. Ulukan (2015) highlighted that design and accident rates in workplace have a high correlation, so that health and safety needs should be met at the design stage[17]. According to this study, the most important barriers implementing health and safety considerations into the design process are the lack of knowledge of both designers and specialists, and the incomplete development of the health and safety culture in workplace.

Since almost all occupational accidents occurring in this sector are the incidents that take place on the site during the construction process, it is considered that measures should be taken on the construction site when it occurs. Because of this approach, occupational safety is often not an issue to be thought until the construction starts. The solution of this problem which is ignored by the designer is left to the occupational health and safety specialists, because it is perceived as a construction phase problem. However, designers are among the main stakeholders of the system who aim to solve spatial, structural and mechanical problems by constructing the structure in a virtual environment before actually building it. Even work safety is not an obvious job description for the designer, like other problems related to the construction, it is directly involved in the designer's field. For instance, the aesthetics of the parapet walls are designed in harmony with the exterior appearance of the building. Building this walls in advance may naturally mean a measure against falling, and the risk of falling can be greatly reduced by these decisions at the design stage[9].

\section{Research Methods}

A questionnaire called "Prevention of Occupational Accidents in Construction Sector through Design" was conducted for the purpose of determining the awareness of the stakeholders in the Turkish construction sector about the concept of safety by design. A preliminary letter was prepared explaining the purposes of the study and the method of conducting it.

\subsection{Organization of the Questionnaire}

A 13-question questionnaire was carried out with designers (architects, civil engineers) and occupational health and safety specialists, which are part of safety by design stakeholders. While these 13 questions are categorical, there are 6 open-ended options. The first two questions were related to the participants, directly. The first question is about the participants' positions in the company they work for (project manager, architect, civil engineer and occupational safety specialist), and the second question was about determining their experiences in the sector. The next two questions were related to the size of the companies and their experiences by year in the sector. The fifth question was about the hazard analysis carried out before the construction start date. The sixth question concerned the use of personal equipment provided to employees. The seventh question aimed to determine what kind of projects companies usually perform. The eighth and ninth questions focused on the causes and responsible of occupational accidents in the sector. The tenth and eleventh questions were dealt with the occupational safety through design. The twelfth question aimed to identify the factors considered by the designers at the design stage which may contribute to occupational safety. The last question of the questionnaire was to determine the benefits of safety through design.

\subsection{Sample}

This study, which aims to investigate the effect of prevention through design on construction accidents in construction sector, includes designers (architect, civil engineer), project managers and occupational safety specialists. Once the target respondents were identified, the communication was established with the registered participants of The Union of Chambers of Turkish Engineers and Architects via e-mail and face-to-face interviews. The questionnaire was evaluated within the framework of the responses of 244 participants out of $1189(20 \%$ return rate).

\section{Research Findings and Discussion}

Findings for the respondents were given in Table 1. As shown in Table 1, 42.21\% of the respondents from the construction sector are civil engineers, $33.20 \%$ are architects, $16.39 \%$ are occupational safety specialists and $8.20 \%$ are project managers. Table 1 also shows the distribution of participants according to their experience in the sector by years. $41.80 \%$ of the participants have $4-10$ years experience, $22.54 \%$ have $1-3$ years experience, $18.85 \%$ have $11-20$ years experience and $16.81 \%$ have more than 20 years experience. 
Table 1. Findings for the respondents

\begin{tabular}{ccccc}
\hline \hline $\begin{array}{c}\text { Positions in the } \\
\text { company }\end{array}$ & Project Manager & Occupational Safety & Specialist & $\% 42.21$ \\
& $\% 22.54$ & $\% 41.80$ & Architect & Civil Engineer \\
$\begin{array}{c}\text { Experiences in the } \\
\text { sector }\end{array}$ & $1-3$ years & $4-10$ years & $11-20$ years & $20+$ years \\
\hline \hline
\end{tabular}

Table 2 presents the distribution of the companies employed by the participants according to the number of employees, and the years of experience in the sector. Distribution of companies by number of employees are; $43.03 \%$ of them have $1-10$ people, $33.61 \%$ have over 50 people, $10.25 \%$ have $11-20$ people, $6.56 \%$ have $31-50$ people, and $6.56 \%$ have $21-30$ people. In terms of corporate age, $34.43 \%$ are over 20 years, $22.95 \%$ are 6 to 10 years, $21.72 \%$ are 0 to 5 years, $11.07 \%$ are 11 to 15 years, and $9.84 \%$ of them have been operating in the sector for 16 to 20 years.

Table 2. Size of the companies employed by the participants

\begin{tabular}{lccccc}
\hline \hline $\begin{array}{l}\text { Number } \\
\text { of } \\
\text { employees }\end{array}$ & $\% 43.03$ & $\% 10.25$ & $\% 6.56$ & $\% 6.56$ & $\% 33.61$ \\
& $1-10$ person & $11-20$ person & $21-30$ person & $31-50$ person & $50+$ person \\
$\begin{array}{l}\text { Corporate } \\
\text { Ages }\end{array}$ & $\% 21.72$ & $\% 22.95$ & $\% 11.07$ & $\% 9.84$ & $\% 34.43$ \\
& $0-5$ years & $6-10$ years & $11-15$ years & $16-20$ years & $20+$ years \\
\hline \hline
\end{tabular}

Figure 1 is concerned whether the companies of the participants are conducting a job hazard analysis before starting work. It was observed that $54.10 \%$ of the participants did hazard analysis, while $45.90 \%$ of them did not.
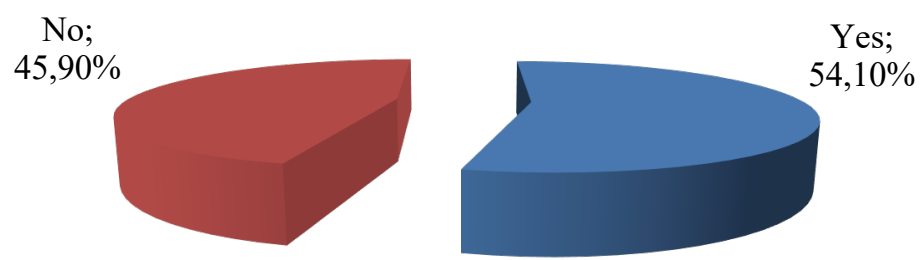

Figure 1. Distribution of companies to conduct job hazard analysis

When the results are analyzed by firm size, it is seen that the rate of hazard analysis is higher in large and medium sized companies as shown in Table 3.

Table 3. Distribution of hazard analysis ratios according to size of companies

\begin{tabular}{cccc}
\hline \hline Number of employees & Yes & No & Total \\
& $\% 40,95$ & $\% 59,05$ & $\% 43,03$ \\
$1-10$ person & 43 & 62 & 105 \\
& $\% 36$ & $\% 64$ & $\% 10,25$ \\
$11-20$ person & 9 & 16 & 25 \\
& $\% 75$ & $\% 25$ & $\% 6,56$ \\
$21-30$ person & 12 & 4 & 16 \\
& $\% 75$ & $\% 25$ & $\% 6,56$ \\
$31-50$ person & 12 & 4 & 16 \\
& $\% 68,29$ & $\% 31,71$ & 823,61 \\
$50+$ person & 56 & 26 & 244 \\
\hline Number of participants & 132 & 112 & \\
\hline \hline
\end{tabular}


The distribution of safety related equipment that the companies of the participants provide their employees before starting to work is presented in Figure 2. Participants state that $88.11 \%$ of the companies provide head protection, $75.41 \%$ hand protection, $66.39 \%$ fall protection, $64.34 \%$ eye protection, $39.75 \%$ ear protection equipment, and $7.79 \%$ of the companies do not supply any safety related equipment. The other option offered to the participants corresponds to a rate of $10.66 \%$. The details of the answers given to the other option of the participants are $9.0 \%$ steel toe shoes, $0.40 \%$ dust mask, $0.40 \%$ gas mask and $0.86 \%$ reflector vest.

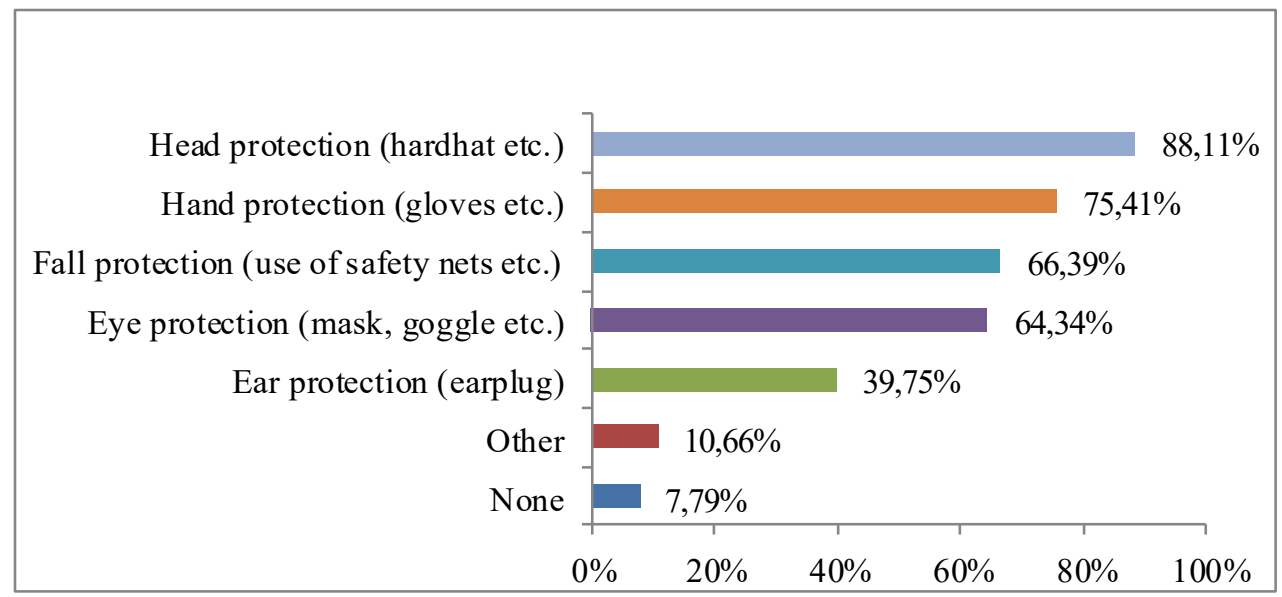

Figure 2. Distribution of personal equipment provided to employees

Figure 3 shows the distribution of the project types of the companies involved. It was found that $69.26 \%$ of them worked on residential buildings, $36.07 \%$ on mixed structures, $30.33 \%$ on industrial structures, $23.77 \%$ on office buildings, $17.62 \%$ on infrastructure projects, $15.97 \%$ on education buildings, $13.52 \%$ on dam, bridge, road construction, $12.30 \%$ on transportation structures, $9.84 \%$ on health structures, and $7.79 \%$ on tourism structures.

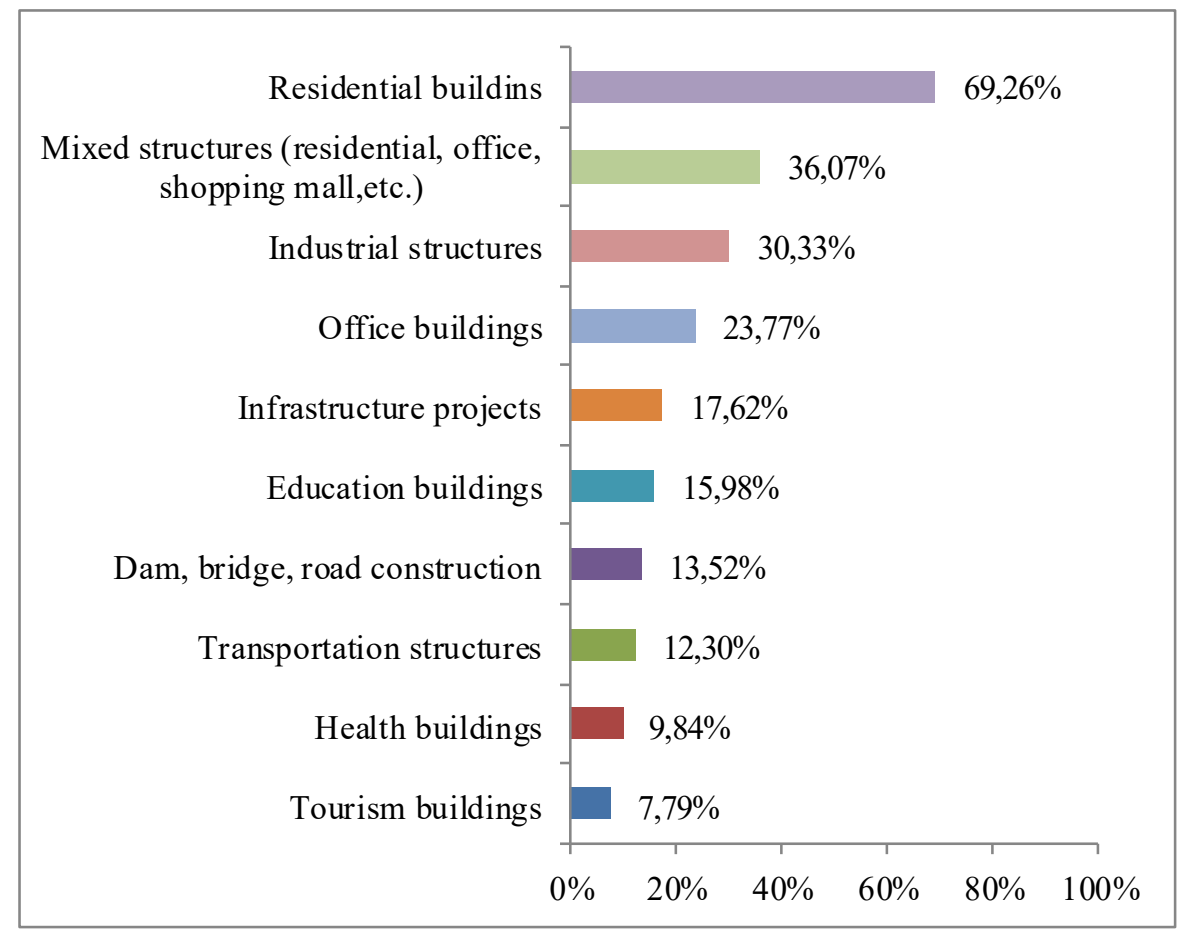

Figure 3. Distribution of the project types of the companies involved

In Figure 4, the participants were asked about the most important reasons of occupational accidents in the construction industry. According to this question, the three most important causes of occupational accidents are; missing or insufficient safety measures $(84.43 \%)$, accident prone workers existence $(56.56 \%)$, and long working hours (overtime, multiple shifts, etc., 33.61\%). The responses given by the participants to the optional open-ended questions are; not doing risk analysis correctly, not fully established occupational health and safety culture in the company, lack of supervision and dissuasive penalties, and the need for immediate completion of the project. 


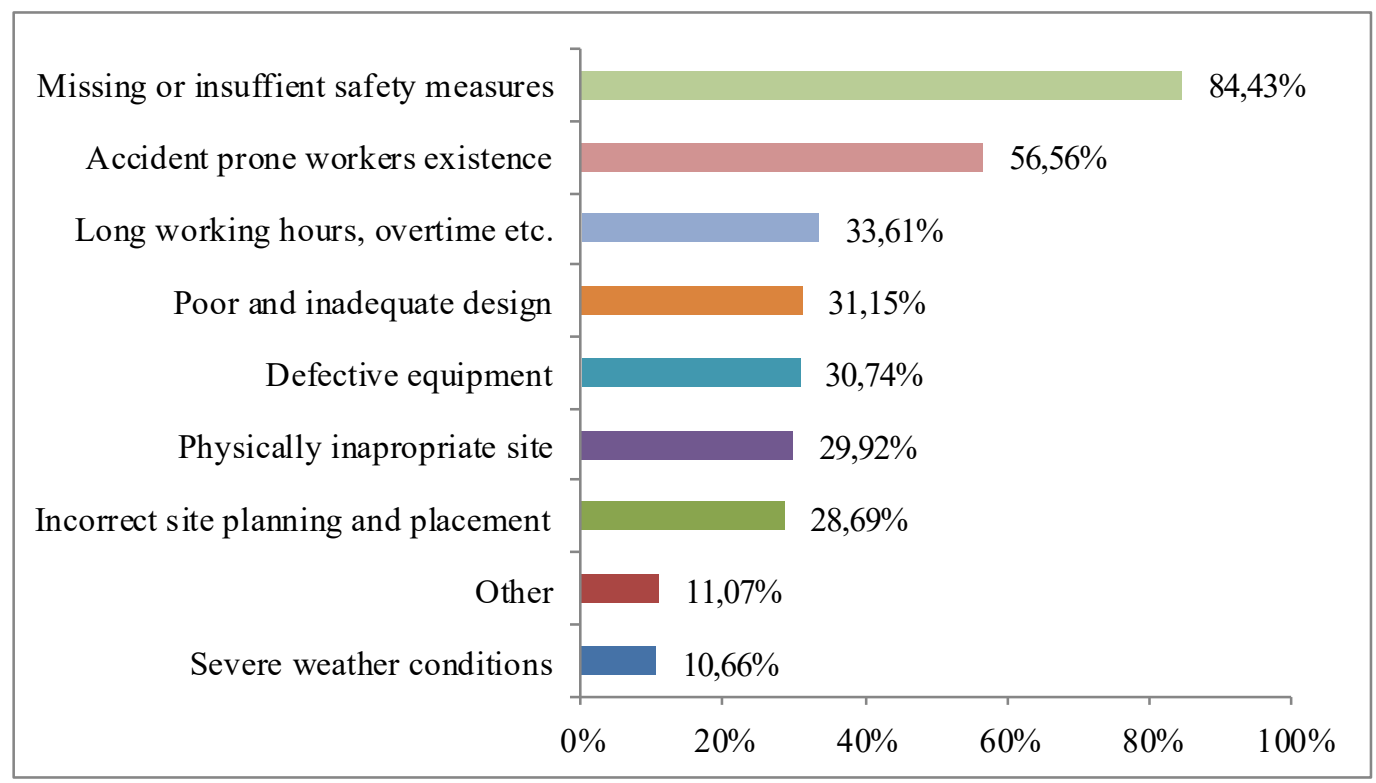

Figure 4. Causes of occupational accidents in the construction sector according to the participants.

The responses of the participants to the question of who they see as responsible for the accidents in the construction sector are shown in Figure 5. Contractors $(68.44 \%)$ and construction workers $(68.03 \%)$ are found to be the two most important responsible for accidents in the sector. Based on the given answers, employers (55.33\%) and official authorities $(29.10 \%)$ are in the third and fourth places respectively and both groups play an important role in accidents. In addition, $17.21 \%$ of the respondents see the designers as responsible, proving that designers take roles in accidents. The other responses for the open-ended option are construction supervisor, inspectors and occupational safety specialists have been held responsible for the accidents in the construction sector.

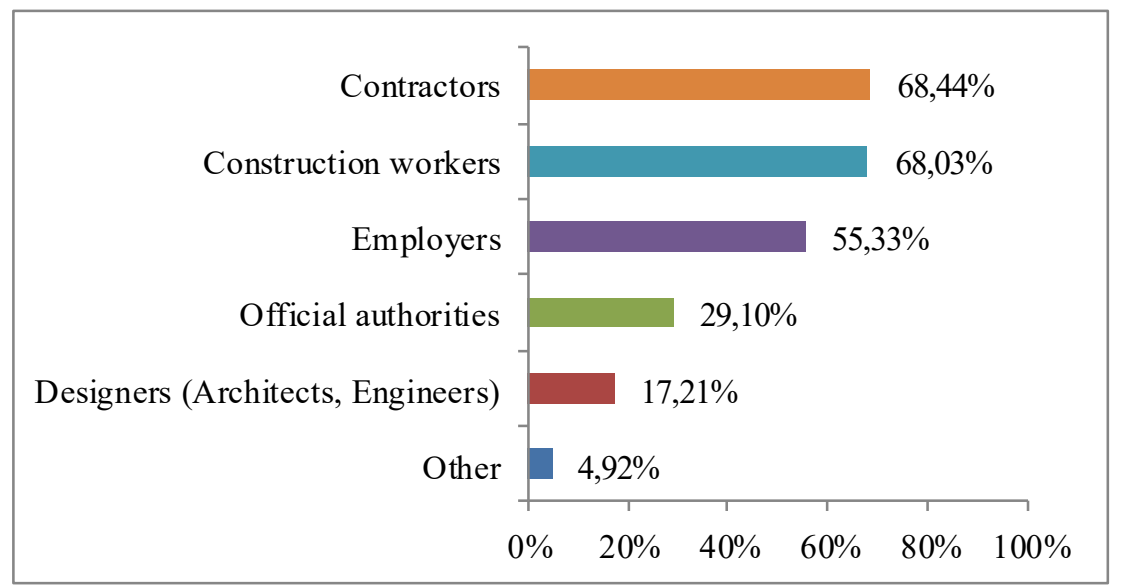

Figure 5. Responsible for occupational accidents in the construction sector according to the participants

The responses regarding whether the participants have knowledge about "Occupational Safety by Design" are given in Figure 6. It is seen that $69.26 \%$ of the participants do not know about safety by design.

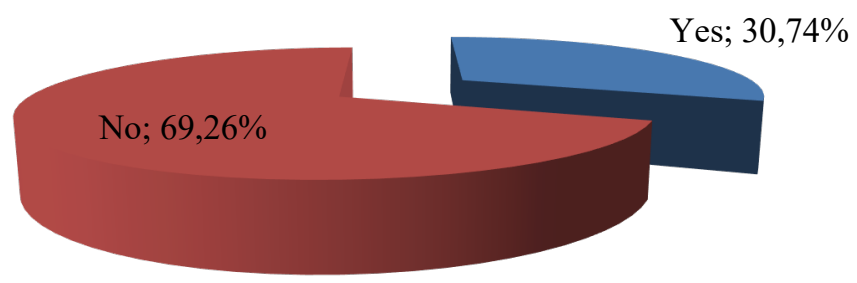

Figure 6. Participants' level of knowledge about safety by design 
The level of knowledge of the different participants about safety by design is shown in Table 4. According to the table, it is seen that occupational safety experts and architects have more knowledge about design and occupational safety.

Table 4. Participants' level of knowledge about safety by design

\begin{tabular}{cccc}
\hline \hline $\begin{array}{l}\text { Positions in the } \\
\text { company }\end{array}$ & \multicolumn{2}{c}{ Participants' level of knowledge about safety by design } \\
& Yes & No & Total \\
& & & $\% 8,20$ \\
Project manager & $\% 30$ & $\% 70$ & 20 \\
& 6 & 14 & $\% 33,20$ \\
Architect & $\% 33,33$ & $\% 66,67$ & 81 \\
& 27 & 54 & $\% 42,21$ \\
Civil engineer & $\% 27,18$ & $\% 72,82$ & 103 \\
& 28 & 75 & $\% 16,39$ \\
Occupational Safety & $\% 35$ & $\% 65$ & 40 \\
Specialist & 14 & 26 & $\% 0$ \\
Other & 00 & 0 & 0 \\
& 75 & 169 & 244 \\
\hline Number of participants & & & \\
& & & 0 \\
\hline \hline
\end{tabular}

The participants were asked about the reasons why they did not conduct a study on the safety of their workers during the design process. According to their answers which is shown in Figure 7; $73.36 \%$ of the participants stated that they have insufficient knowledge and training about the occupational safety, $60.25 \%$ stated that their work on the subject could lead to an increase in the project costs, $40.16 \%$ stated that they do not know its necessity, $33.61 \%$ stated that time was insufficient and $27.46 \%$ stated that they have never thought about the safety during the design phase because of potential legal consequences and responsibility. In addition, the lack of statutory audits and the lack of employers' demands are among the potential reasons according to the answers given to the openended question $(4.10 \%)$.

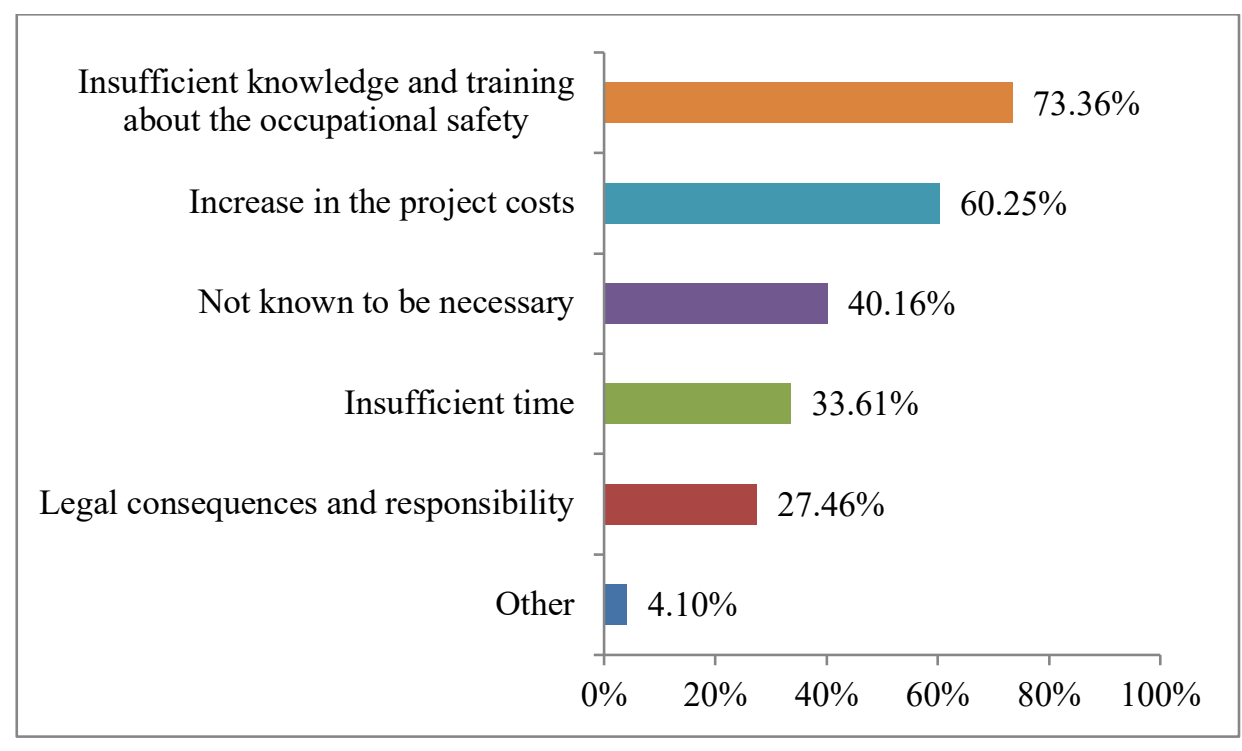

Figure 7. Reasons why participants do not consider occupational safety

The answers of the participants to the questions about the measures that they take during the design phase about the safety of the construction workers are shown in Figure 8. According to the participants, the three most important measures to be taken during the design phase are: the designs against fall $(79.92 \%)$, use of less hazardous building materials and methods (53.28\%) and consideration on ergonomics $(51.23 \%)$. Participants think that prefabricated or modular design (39.34\%), which requires less work, will also contribute to occupational safety. Prefabrication reduces the hazard level of a task in two ways. First, it allows the location of the work to be shifted to a lower hazard environment [18]. Second, prefabrication allows the work to be shifted from the field to a factory, which allows the use of safer, automated equipment, such as for cutting and welding[7]. However, $4.10 \%$ of the participants agree that none of these measures will contribute to occupational safety at all. 


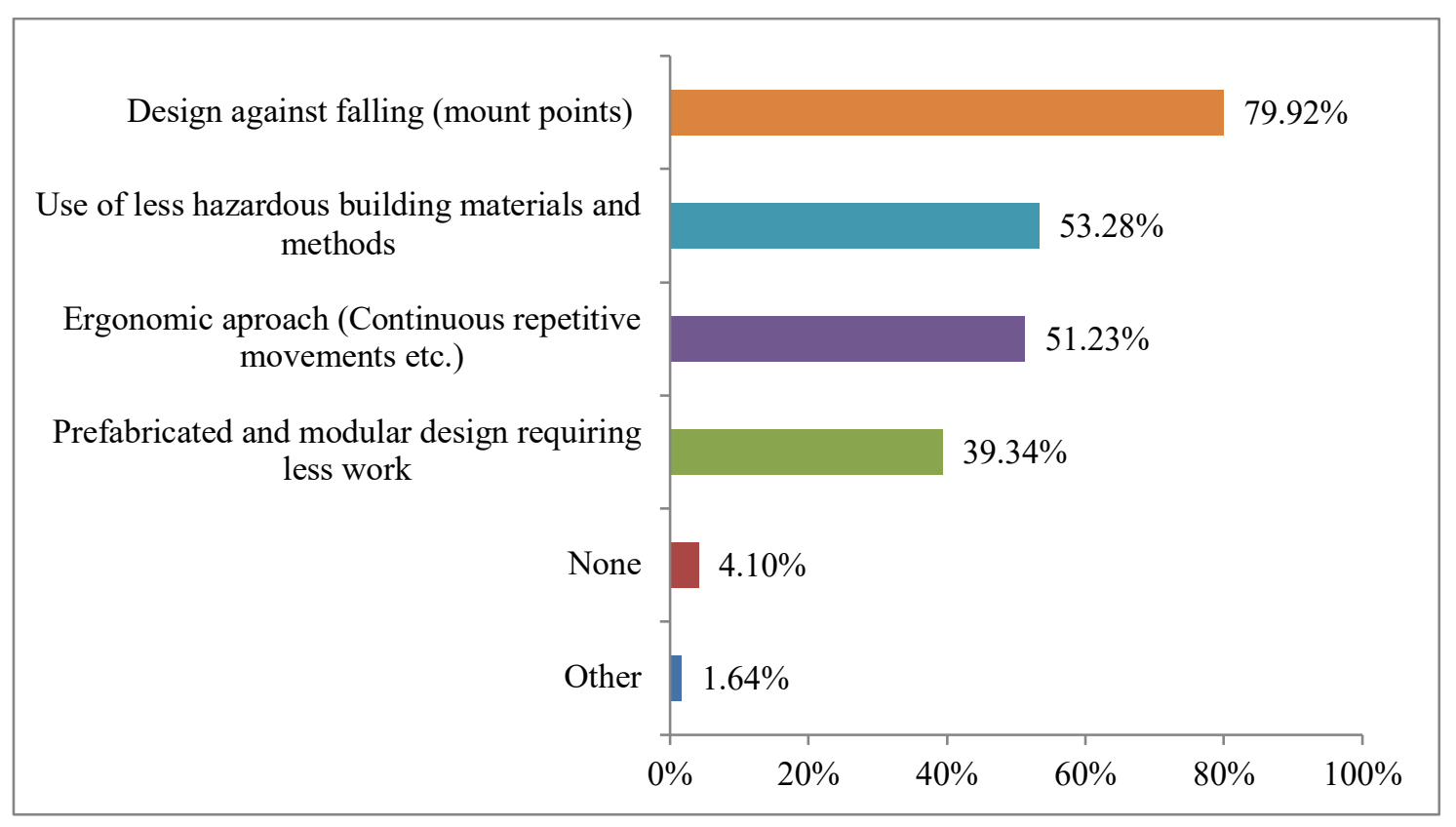

Figure 8. Measures that may be included in the design for the safety of the workers

The factors that are expected to be decreased with the implementation of safety by design in the construction industry are indicated in Figure 9. 90.16\% of the participants agree that risks of injuries and fatalities will decrease with a safety through design approach. Prevention of construction delays, reduction of insurance and construction costs are other important benefits to be obtained. On the other hand, $7.79 \%$ of the respondents stated that this approach will have no effect on any of them.

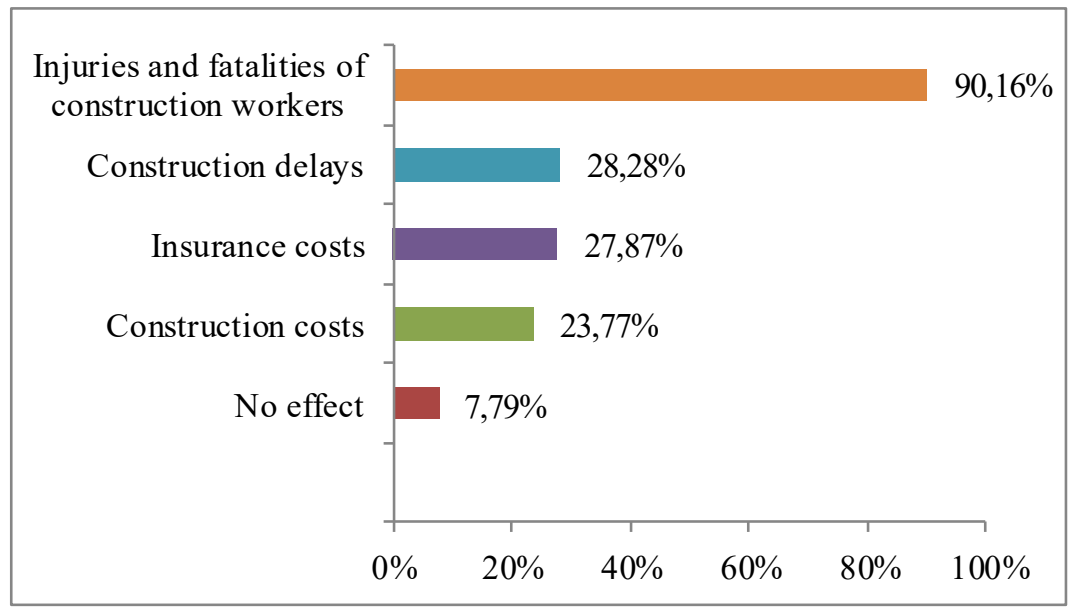

Figure 9. Factors to reduce work safety with design

\section{Results}

Safety by design concerns the pre-construction stage. During the design phase; the designer has a great deal of work to ensure that all safety issues are adequately assessed whether the design involves any dangerous construction applications. In this assessment, designers are expected to analyze unpredictable risks. However, the designer cannot be expected to be an expert in all aspects of construction techniques and safety. Therefore, the designer should work with other stakeholders such as project manager, site supervisor, occupational safety specialist. Designers working with various participants (expert consultants, employers, users, project managers, construction workers) in the design process will greatly help in identifying the safety risks associated with the design, based on previous experience. 
Designers should start by determining the risks derived from the design. Draft design should be reconsidered in terms of risks and reassessed from the perspective of other stakeholders. If the proposed solutions for the risks identified by other participants does not impair the originality of the design, they can be included in the design. If not, all end-users in the project lifecycle should be informed about that risk. Both in this study and in the other studies examined, it has been emphasized that occupational safety is a concept that should be considered from the beginning of the design. The importance and definition of safety by design has been made by institutions, regulations and researchers in many countries. As can be seen from the questionnaire results, the knowledge of safety by design is not common in Turkey. It is obvious that those who know about this concept have deep hesitations about implementation. Even though the sector awareness has emerged in terms of the benefits to be achieved through the implementation of safety by design, there is still a huge gap in terms of implementation. It may be possible to fill this gap by increasing statutory audit and penal sanctions.

Studies show that designers can prevent occupational accidents to a great extent. What really needs to be underlined is how designers can implement safety by design. Designers should consider occupational safety as an important parameter in their designs. There are some important issues that can contribute to occupational safety like: incorporating the understanding that safety by design is an integral part of the design process in the education programs of universities in order to increase the awareness of designer, introducing certain legislations and obligations related to safety, and issuing regulations on safety issues that concern designers' designs.

Increasing the heights of parapet and guardrail to at least $110 \mathrm{~cm}$ by building by laws, and implementing the improvements, such as the publication of regulations on personal safety equipment are the indicatives of the development of safety by design as a concept in Turkey. With respect to the results of this study; the subjects of the most common accidents in the construction sector are the low precautions against falling, dangerous construction methods and the lack of ergonomically feasible working conditions. Considering the most important reasons of accidents, the issues that designers should take into consideration in their designs are;

- The height of the parapet

- Types and materials of roofing

- Types of flooring materials and applications

- Materials of facade and construction methods

- Ease of application and health effects of materials

- Ergonomics in the workplace

- Production priority and ranking

- On-site work plan

- Informing users about risks.

The efforts of the designers to prevent occupational accidents during the design phase become less expensive considering the costs of accidents and the safety measures to be taken on site afterwards.

\section{References}

1. G.Carter and S. Smith, "Safety Hazard Identification on Construction Projects." Journal of Construction Engineering and Management, 132(2), (2006), 197-205.

2. W.Wang, J. Liu, \& S.Chou, "Simulation-Based Safety Evaluation Model Integrated with Network Schedule." Automation in Construction, 15(3),(2006), 341-354.

3. J.J. Lew and T.J. Lentz, "Designing for Safety - Applications for the Construction Industry.", 18th CIB World Building Congress, United Kingdom, (2010), 37-45.

4. SİG Meclisi’nin İlkeleri, İşleyişi, İşçi Sağlığı ve İş Güvenliği Meclisi (2018), Accessed March 10, 2019. Retrived from http://www.guvenlicalisma.org/site_icerik/2019/3mart/2018_ic.pdf

5. T.C. Çalışma ve Sosyal Güvenlik Bakanlığı İş Teftiş Kurulu Başkanlığı, Yapı İşlerinde İş Sağlığı ve Güvenliği Teftiş Projesi Genel Değerlendirme Raporu, (2007), Ankara.

6. F.A. Manuele, "Principles for the Practice of Safety." American Society and Safety Engineers, 4(7), (1997), 27-31.

7. T.M. Toole and J. Gambatese "The Future of Designing for Construction Safety." Journal of Safety Research, 39, (2008), 225-230.

8. X. Sun, H. Chong, P. Liao, D. Fang, and Y. Wang, "A System Dynamics Model of Prevention through Design towards Eliminating Human Error.", KSCE Journal of Civil Engineering, 23(5), (2019), 1923-1938.

9. G.E. Gürcanlı, "Yeni ve Zorunlu Bir Kavram Olarak "İş Güvenliği İçin Tasarım.". 3. İşçi Sağlığı ve İş Güvenliği Sempozyumu, Çanakkale, (2011),133-141.

10. Gambatese J. and Hinze J., Addressing Construction Worker Safety in the Design Phase: Designing for Construction Worker Safety, Automation in Construction, 8(6),(1999), 643-649. 
11. N. Tymvios, M. Behm, J. Gambatese, H. Lingard, A. G. Gibb, J. Smallwood, \& C., McAleenan, "Benefitting Workers and Society Through Inherently Safe(r) Construction." Revisiting Lorent. In Proceedings of CIB W099, Belfast,(2015),449-457.

12. D. M. Aires, M. C.Rubio, \& A. G. F. Gibb, "The Impact of Occupational Health and Safety Regulations on Prevention Through Design in Construction Projects: Perspectives from Spain and the United Kingdom." Journal of Prevention, Assessment \& Rehabilitation, 53(1), (2016), 181-191.

13. R. Lopez, P. E. Love, D. J. Edwards, and P. R Davis, "Design Error Classification, Causation, and Prevention in Construction Engineering.", Journal of Performance of Constructed Facilities, 24(4), (2010),399-408.

14. M.Dalton, "Fatal Accidents in the Irish Construction Industry 1991-2001: A Survey of Contributory Factors." Health and Safety Authority, (2002), 1-71.

15. M. Behm, "Linking Construction Fatalities to the Design for Construction Safety Concept. Safety Science, 43(8), (2005), 589-611.

16. S. H. Gürsoy, "Risk Yönetimi Çerçevesinde Türkiye'de Mevzuata Uygun Bir Güvenli Tasarım Modeli.", İstanbul Teknik Üniversitesi Fen Bilimleri Enstitüsü Mimarlik Anabilim Dalı Doktora Tezi, (2014),1-229.

17. Ş. E. Ulukan, "Sağlık ve Güvenliği Tasarlamak.”, Mimarlık Dergisi, (2015), 384.

18. Gambatese, J. A., J. Hinze, and C. T. Haas, “Tool to design for construction worker safety.” ASCE J. of Arch. Eng. (1997), 3(1): 32-41. 